\title{
A New Perspective on Innovation Driving Global Value Chains Upgrading of High-Tech Industries: Evidence from China
}

\author{
Yuanyuan Shan, Wei Zhang \\ School of Economics, Wuhan University of Technology, Wuhan, China \\ Email: 489517109@qq.com
}

How to cite this paper: Shan, Y.Y. and Zhang, W. (2019) A New Perspective on Innovation Driving Global Value Chains Upgrading of High-Tech Industries: Evidence from China. American Journal of Industrial and Business Management, 9, 834-844.

https://doi.org/10.4236/ajibm.2019.94056

Received: March 11, 2019

Accepted: April 8, 2019

Published: April 11, 2019

Copyright $\odot 2019$ by author(s) and Scientific Research Publishing Inc. This work is licensed under the Creative Commons Attribution International License (CC BY 4.0).

http://creativecommons.org/licenses/by/4.0/

\begin{abstract}
High-tech industries and their upgrading along global value chains are the important parts of China's future industry development. The process of innovation promoting global value chains upgrading of high-tech industries is affected by four factors, namely, the innovation input, the innovation carrier, the innovation culture and the innovation market. If analyzed by the chemical reaction equation, the innovation input is considered as the reactant, the output is the resultant, the innovation carrier is the catalyst, the innovation culture is the equivalent to the reaction conditions, and the innovation market has the selection to the resultant. The final chosen innovation achievement can bring high-tech industries with product upgrading, process upgrading, function upgrading and value chain upgrading. Through the empirical test, it finds that the innovation input, the innovation market and the innovation culture have obvious effects on global value chains upgrading of high-tech industries, but the innovation carrier not.
\end{abstract}

\section{Keywords}

High-Tech Industries, Global Value Chains, The Innovation Input, The Innovation Carrier, Chemical Reaction Perspective

\section{Introduction}

During the time of knowledge-based economy, the developed countries have put forward new strategies to support, promote and develop their technological innovation and upgrading of their manufacturing industries. At the same time, China has also promulgated "Made in China 2025" as a ten-year action plan to implement manufacturing power strategy. Chinese government thinks highly of 
accelerating the development of high-tech industries and promoting industries to the high position in global value chains. Since high-tech industries are the direction of industrial transformation and upgrading and the strategic support for building a modern economic system.

However, China as a manufacturing powerhouse, though trying hard to participate in the division of global value chains, has been locked in low value-added position in the global value chains. Furthermore, because the global value chains division system is mature nowadays, it's difficult for Chinese traditional manufacturing industries to achieve value chains climbing. But high-tech industries are more relying on new technology, so they have more opportunities to catch up with developed countries and enter high value-added position in global value chains.

In previous scholars' research, independent innovation is considered as an important approach to achieve global value chains upgrading of high-tech industries. This paper takes the analytical framework of chemical reaction equation into the process of innovation driving global value chains upgrading of high-tech industries. With this analytical framework, various factors of independent innovation can be divided into four types. Different function of each type on global value chains upgrading can be found. This will provide theoretical basis and decision-making reference for scientific formulation of strategic planning and policies for the development of high-tech industries, and promotion of international competitive advantage of high-tech industries.

The paper first introduces the significance of introducing chemical reaction equation into the analysis of global value chains upgrading, which is the main innovative idea; then after a literature review, it defines the purpose of the research. It analyses the influencing factors on global value chains upgrading of high-tech industries. By analyzing the different effects of different factors of technological innovation, it combines them with various parts of chemical reaction equation, and summarizes the results of the impact of technological innovation on global value chains upgrading of high-tech industries under the framework of chemical reaction equation. In empirical test, the multiple regression model is constructed and tested. From the results, it analyses the independent innovation driving force in global value chains upgrading of China's high-tech industries. Finally, based on the problems and analysis, the corresponding countermeasures and suggestions are put forward.

\section{Literature Review}

Global Value Chain Theory has attracted great attention from academia since proposed. Under the background of economic globalization, the links a country's industries or enterprises embedded in determine their positions in division system of global value chains. China accelerated its integration into global value chains from 2000 to 2011, but its position shifted downstream, showing signs of low-position lock-in of global value chains. But the forward participation of ad- 
vanced manufacturing industries and knowledge-intensive service industries in global value chains has been further enhanced since 2012 [1]. Since the 1990s, China's high-tech industries have been growing rapidly, which has a breakthrough driving role in economic growth and industrial structure upgrading [2]. The proportion of added value of high-tech industries in the world has reached the first place. China has increased from $3.6 \%$ in 2000 to $29.08 \%$ in 2015 , while the United States has decreased from $37.75 \%$ in 2000 to $28.94 \%$ in 2015 [3].

Existing studies on global value chains mostly focus on the measurement of division position and its influencing factors. At present, there are many methods to measure the division position in global value chains, such as GVC index, technical sophistication of export products, upstream index, vertical specialization or industrial integration, etc. The technical sophistication of export products was first proposed by Hausmann [4]. Many scholars use this index to analyze division position of China or other countries in global value chains from the national level, regional level or industrial level. When Rodrik studied the difference of export sophistication between developed and developing countries, he found that the export sophistication of developing countries such as China and India remained at a high level from 1992 to 2003, significantly higher than their own economic development level [5]. This is known as the "Rodrik Paradox". To solve this problem, scholars have made improvements in models and methods. Amiti and Freund consider the impact of processing trade and that the processing trade part of export trade should be excluded from the export sophistication model [6]. Xu, B. weights the income level of the model from the perspective of regional heterogeneity in China, and finds that the "Rodrik Paradox" weakens by $30 \%-80 \%$ [7].

Many scholars have studied influences of independent innovation on global value chains upgrading of high-tech industries. Haichao L., Zhichun L. and Yang Y. have divided the influencing factors into internal factors and external factors [8]. Others according to the connotation have summarized such factors: technological factors, scale economy, export scale, production benefits, government support, financial market [9], FDI [10] and processing trade [11]. The most important difference between high-tech industries and traditional industries is technology. Technological innovation is an important factor affecting export sophistication. Lin S. found that technological innovation ability promotes export sophistication of high-tech manufacturing industries in China by empirical analysis [12]. Some other scholars thought that technological innovation efficiency promotes export sophistication [13] [14].

It's seen that the existing literature constantly revises the calculation model of global value chains position, and the calculation method is increasingly perfect. The use of export product sophistication index to calculate the division of labor position in global value chains has been recognized by the academic community. Technological innovation is an important factor affecting the division position in global value chains has been tested by empirical evidence. However, what are the main innovative factors driving global value chains upgrading of high-tech 
industries? This needs further theoretical analysis and empirical testing.

\section{Analysis of Innovation Driving Force in High-Tech Industries}

Technological independent innovation has a great impact on global value chains upgrading of high-tech industries. The technological independent innovation can also be divided into the following four factors.

\subsection{The Innovation Input}

The innovation input is the origin of independent innovation. With adequate innovation input, innovative activities can create new technologies and products, which may achieve process upgrading, product upgrading, function upgrading and value chain upgrading. It is divided into talents input and R\&D investment.

Talents are the operators of technological innovation. The number of advanced technological and intellectual talents has a positive correlation with technological innovation. The more people involved in innovation research, the more likely new knowledge, new technology and new products will be generated. In a word, talent capital is the root of new knowledge and technologies, which is a fundament of innovation-driven development and transformation.

$\mathrm{R} \& \mathrm{D}$ investment is the guarantee of invention and creation. Only when the research funds are sufficient, can high-tech talents study new problems, invent new technologies and apply them to practice, so as to realize industrial technological innovation. Chao-Hung, W. uses panel data of high-tech industries to prove that $R \& D$ investment is positively correlated with innovation performance [15]. In view of the history, each invention was born with countless efforts and expenses, if there weren't enough funds to support, the new invention wouldn't have been able to appear.

\subsection{The Innovation Market}

Will technology spillover effect ultimately promote industries to enter the high value-added position of global value chains? It depends on the market recognition. Meanwhile, the market demand of new technology is the key factor of knowledge and technology spillover and diffusion. On the one hand, the innovation market can quickly match the innovative resources. It will save the preparation time for technological innovation. On the other hand, the market demand can generate industrial traction to promote the formation and development of new industries through adjusting ROI (return on investment) and profit level. Therefore, market demand is the power source of independent innovation. In today's industrial distribution and development pattern, the market demand of innovation may cause the enterprises relying on technology introduction and imitation to lose their competitive advantage, but the other enterprises relying on independent innovation to walk in the forefront of industrial competition. Especially, the high-tech industries can quickly occupy the market, gain a lot of 
profits, quickly climb to the high value-added position of global value chains, and even establish a new global value chains division system with China's high-tech industries as the core.

\subsection{The Innovation Carrier}

The innovation carrier is an important catalyst for innovation driving global value chains upgrading of high-tech industries. It can not only provide a good incubation environment for innovation, but also make it possible for rapid transformation of innovation achievements. The typical representatives of the innovation carrier include high-tech industrial parks and high-tech development zones at all levels. Those facilities will achieve clusters of high-tech industries, and promote the formation of an integrated organization centered on high-tech enterprises and supported by universities and scientific research institutes. Also those facilities can provide innovation activities with ancillary services like information exchanging, technology standardization supporting and technology achievement transforming.

\subsection{The Innovation Culture}

The innovation culture includes mode of thinking, sense of value, atmosphere of spirit and code of conduct. It cultivates innovation awareness, encourages innovation achievement transformation, tolerates the risk of innovation failure and respects the right of innovation achievement. Therefore, the innovation culture is the soil for the survival and development of independent innovation, and the greenhouse for nurturing new technologies and industries.

The concrete manifestation of innovation culture in enterprises is "entrepreneurship". Entrepreneurship is a sense of innovation awareness and behavior. It reflects the basic abilities of the excellent entrepreneurs to tap new opportunities, to utilize potential resources and to open up new markets. It can strengthen the relevance degree between enterprise and technology, and help to build up core competitiveness. The fundamental task of entrepreneur is to transform the achievements of independent innovation into real productive forces. Therefore, an innovative leader is the guarantee for an enterprise to achieve innovative development.

\subsection{Summary}

Essentially, independent innovation is a process that the innovation input under the control of the innovation culture produces the innovation achievements which meet the demand of the innovation market in the innovation carrier. Those achievements will bring about product upgrading, process upgrading, function upgrading and even promote the whole industry to enter the new position in global value chains. Different functions of the four factors of independent innovation can be analogized to four parts of chemical reaction equation: reactant, resultant, catalyst and reaction condition.

Reactant is the origin of chemical reaction. Increasing the reactants will facili- 
tate the chemical reaction, just like the innovation input. Resultant is the output of chemical reaction, like the innovation achievement. Removing unwanted resultant and purifying needed resultant can both facilitate the reaction too. It works like the innovation market. Catalyst is the most common means of increasing the rate of chemical reaction. It can reduce activation energy required for chemical reaction to increase the exchange rate of reactant, which is similar to the innovation carrier's industrial clusters effect. Reaction condition is the key to start chemical reaction as well as the innovation culture to independent innovation.

Therefore, the innovation input has the fundamental function during the innovation driving global value chains upgrading of high-tech industries. And the innovation market, the innovation carrier and the innovation culture can increase the global value chains upgrading rate.

\section{Empirical Test of Global Value Chains Upgrading of High-Tech Industries}

\subsection{Hypothesis}

This paper uses regression analysis of panel data to investigate the relationships between independent innovation and global value chains upgrading of high-tech industries, and to find the different functions of four factors. According to the previous analysis, four hypotheses can be suggested as follows:

H1: Increasing the innovation input has a significant role in promoting global value chains upgrading of high-tech industries.

H2: Expanding the innovation market has a significant role in promoting global value chains upgrading of high-tech industries.

H3: Developing the innovation carrier has a significant role in promoting global value chains upgrading of high-tech industries.

H4: Promoting the innovation culture has a significant role in promoting global value chains upgrading of high-tech industries.

\subsection{Model Setup}

According to the previous analysis, four factors of independent innovation are the explanatory variables; the position in global value chains is the interpreted variable; factor structure, industry scale and economic environment are all taken as control variables. Therefore, the model is as the following:

$$
\mathrm{TSI}_{i t}=\alpha_{0}+\alpha_{1} \mathrm{INO}_{-} \mathrm{I}_{i t}+\alpha_{2} \mathrm{INO}_{-} \mathrm{M}_{i t}+\alpha_{3} \mathrm{INO}_{-} \mathrm{A}_{i t}+\alpha_{4} \mathrm{INO}_{-} \mathrm{U}_{i t}+\alpha_{5} C_{i t}+\varepsilon_{i t}
$$

In this model, INO_I is the innovation input, INO_M is the innovation market, INO_A is the innovation carrier, INO_U is the innovation culture, $i$ is the kind of industry, $t$ is the year, TSI means the position in global value chains, $C$ is the aggregate of control variables.

\subsection{Measures and Data}

This paper uses industry technical sophistication index (TSI) to measure the po- 
sition in global value chains. Its computational method refers to Long, W. and Lei, W. [16], replacing total export with export value added. The formula is as the following:

$$
\operatorname{TSI}_{j k}=\frac{\operatorname{VAX}_{j k} / \operatorname{VAX}_{j}}{\sum_{j} \operatorname{VAX}_{j k} / \sum_{j} \operatorname{VAX}_{j}} Y_{j}=\operatorname{RCA}_{j k} Y_{j}
$$

The $j$ is the economic entity; $k$ is the kind of industry; $\operatorname{VAX}_{j k}$ is the export value added of $k$ industry in $j$ economic entity; $\operatorname{VAX}_{j}$ is total export value added in $j$ economic entity. $Y_{j}$ is the per Capita GDP of $j$ economic entity.

The innovation input is measured by $R \& D$ full-time personnel equivalence and $\mathrm{R} \& \mathrm{D}$ investment. The innovation market is measured by sales of new product. The innovation carrier is measured by number of national high-tech industrial parks. The innovation culture is measured by the number of private enterprises. Factor structure is measured by per capita net fixed assets (KL). Industry scale is measured by the total output value of industry (OP). Economic environment is measured by the profit growth rate of industry (PG).

Data sources are as follows in Table 1, all data are calculated from raw data from the following Yearbooks. The time span of all Yearbooks is from 2000 to 2014, because the latest data of WIODs are updated to 2014.

\subsection{Measures and Data}

This paper chooses 15 manufacture industries and 3 high-tech industries as the sample by comprehensively considering industrial classification criteria between different databases.

Before the regression analysis, the ADF method is taken to test the robustness of each variable and all variables passed the stationarity test at $5 \%$ significant level.

Regression results are as follows in Table 2.

From the result, it's found that all symbols of variables are "+". It means all factors can promote global value chains upgrading to varying degrees as the theoretical analysis before.

Table 1. Data sources.

\begin{tabular}{cc}
\hline Name of variables & \multicolumn{1}{c}{ Sources } \\
\hline TSI & WIODs, China Statistical Yearbook \\
INO_I & China Science and Technology Statistical Yearbook \\
INO_M & China Science and Technology Statistical Yearbook \\
INO_A & China High-tech Statistical Yearbook \\
INO_U & China Industry Statistical Yearbook \\
KL & China Industry Statistical Yearbook \\
OP & China Industry Statistical Yearbook \\
PG & China Industry Statistical Yearbook
\end{tabular}


Table 2. Regression results.

\begin{tabular}{ccc}
\hline Regression results & All manufacture industries & High-tech industries \\
\hline INO_I & $2.92^{* * *}$ & $3.24^{* * *}$ \\
INO_M & $3.44^{* * *}$ & $3.58^{* * *}$ \\
INO_A & 0.165 & 0.281 \\
INO_U & 0.300 & $0.347^{*}$ \\
R2 & 0.512 & 0.612 \\
\hline
\end{tabular}

From the result of all manufacture industries, it's found that the innovation input and the innovation market are significant. It means they both have obvious functions on manufacture industries. And from the result of high-tech industries, all variables passed the significance test except the innovation carrier, and all of the coefficients are bigger than manufacture industries, which mean independent innovation plays a more effective role in promoting high-tech industries than manufacture industries.

The coefficients of the innovation input and the innovation market are 3.24 and 3.58. That means increasing innovation input and improving market environment can promote global value chains upgrading of high-tech industries. But these coefficients aren't much bigger than those of the whole manufacture industries. The reason may be that the technological innovation behavior and the development of new products in high-tech industries are not very different from that in manufacturing industries at present. The development of advanced productive forces is insufficient, and high-tech industries are still engaged in production links with low added value.

The innovation carrier does not pass any significance test, meaning that national high-tech industrial parks, as the innovation carrier, haven't played catalysis function on global value chains upgrading of China's high-tech industries. The reason may be the following: on the one hand, traditional high-tech industrial parks use tax preferential policies as means to attract high-tech enterprises to realize industrial clusters in the park. However, there are still some defects in the certification conditions, which makes many high-tech enterprises, while enjoying the benefits of high-tech certification in the park, still engage in low value added production manufacturing. On the other hand, many high-tech industrial parks are not influential enough to scientifically determine the development direction of high-tech industries. In the management planning of high-tech industrial parks, there is a lack of systematic research on industrial chains, obvious effect of industrial clusters, and sound development of industrial convergence.

Different from in the manufacturing industries, the innovation culture in the high-tech industries passed the significance test. It means that the enterprises of high-tech industries are more willing to achieve innovation. As analyzed before, private enterprises are beneficial for entrepreneurship to work. Therefore, proportion of private enterprises in high-tech industries is larger than that in manufacturing industries. 


\section{Conclusions and Suggestions}

\subsection{Conclusions}

In the process of innovation driving global value chains upgrading of high-tech industries, the function of each driving factor is similar to that of each component in chemical reaction equation. Therefore, just like controlling the change of chemical reaction, some scientific means can be used to change the innovation factors to promote global value chains upgrading of high-tech industries. The empirical results of this paper show that independent innovation can promote global value chains upgrading of high-tech industries through the innovation input, the innovation market and the innovation culture, while the effect of the innovation carrier isn't obvious.

\subsection{Suggestions}

1) Considering Both Quantity and Quality of the Innovation Input

In the process of cultivating the ability of independent innovation, on the one hand, the investment of innovation should be increased. The government should put forward some fiscal policy to encourage more enterprises to invest in R\&D of independent innovation; on the other hand, more attention should be paid to the use of various R\&D investments and the level of talent investment. In general, the biggest problem of high-tech industries is the transformation of technological achievements. Therefore, while increasing innovation investment, improving the quality of innovation investment is an effective means for high-tech industries to build up core competitiveness in global value chains. Long-term stable strategic alliance of industries, universities and research institutes is the most effective form at present. Cooperation should be long-term and stable, which embodies the principle of complementary advantages, risk sharing, benefits sharing and win-win cooperation.

2) Strengthening and Perfecting the Guidance of the Innovation Market

At present, the socialist market economy with Chinese characteristics still needs to be improved and constructed. The government needs to strengthen the guiding mechanism of the market, give full play to the positive role of the invisible hand, let the market choose and encourage innovative behavior, and promote the marketization of new technologies. At the same time, fiscal policies such as consumer subsidies should actively guide and stimulate the new demand of the market to provide new momentum for global value chains upgrading of high-tech industries. The government should provide appropriate protection for the industrialization and marketization of innovative achievements, avoiding the elimination of high-quality innovative achievements by imperfect market mechanism; also should further deepen the opening up, absorb more advanced international innovations, enhance the independent innovation ability of Chinese enterprises, universities and research institutes.

3) Accelerating the Construction and Perfection of the Innovation Carrier

At present, China's high-tech industries infrastructure construction is insuffi- 
cient; the underlying technology and industry infrastructure technology support is still weak; the layout of the whole industry chain is to be completed. Therefore, the government should build a strong industrial infrastructure, by upgrading the basic industrial capacity, consolidating the foundation of industrial development and providing the basic support for the upgrading of high-tech industries. Furthermore, speeding up the construction of high-tech industrial parks can improve the management system of the parks; will make the high-tech industrial parks better shoulder the responsibility of industrial infrastructure construction and give full play to the advantages of industrial clusters effect. Improving the construction of technology service platform is important too, which contributes to information sharing, strengthens the spillover effect of technological innovation, and promotes the innovation drive of China's high-tech industries by the role of industrial clusters of high-tech industrial parks.

4) Actively Cultivating and Promoting the Innovative Culture

To some extent, the Chinese society still lacks the respect and protection of patents, copyrights and other innovative achievements at present, not being well aware of the importance of innovation. Therefore, the government, enterprises and individuals should publicize the importance of innovation to economic development and enhance social awareness of innovation. The government should improve legal system construction to protect innovative achievements, and form a cultural atmosphere of innovating and respecting for innovation. Meanwhile, the government and enterprises should give support and incentives to encourage more innovative behavior and innovative spirit; the government and banks should give appropriate financial support to enterprises with "entrepreneurship".

\section{Acknowledgements}

This paper would like to acknowledge the financial support from the general project of the National Social Science Foundation of China (17BJL015); the Fundamental Research Funds for the Central Universities (WUT: 2018VI1035).

\section{Conflicts of Interest}

The authors declare no conflicts of interest regarding the publication of this paper.

\section{References}

[1] Zhang, H. and Zhai, X. (2018) Characteristics and Enlightenment of China's Participation in Global Value Chains: A Study Based on Production Decomposition Model. The Journal of Quantitative \& Technical Economics, 35, 3-22.

[2] Zhao, Y. (2012) High-Tech Industrial Economics. 2nd Edition, Science Press, Beijing.

[3] Zhao, Y. and Gao, Y. (2019) The Driving Role of Technological Innovation in Global Value Chain Upgrading of High-Tech Industries: Evidence from High-Tech Industries in Hubei Province. Science \& Technology Progress and Policy, 36, 52-60. 
[4] Hausmann, R., Hwang, J. and Rodrik, D. (2007) What You Export Matters. Journal of Economic Growth, 12, 1-25. https://doi.org/10.1007/s10887-006-9009-4

[5] Rodrik, D. (2006) What's So Special about China's Exports? China \& World Economy, 14, 1-19. https://doi.org/10.1111/j.1749-124X.2006.00038.x

[6] Amiti, M. and Freund, C. (2010) The Anatomy of China's Export Growth. In: Feenstra, R.C. and Wei, S.-J., Eds., China's Growing Role in World Trade, University of Chicago Press, Chicago, IL, 35-56.

[7] Xu, B. (2010) The Sophistication of Exports: Is China Special? China Economic Review, 21, 482-493. https://doi.org/10.1016/j.chieco.2010.04.005

[8] Li, H., Li, Z. and Yi, Y. (2017) Research on Driving Factors and Realization Path of Independent Innovation in China's High-Tech Industry. Scientific Management Research, 35, 50-54.

[9] Chen, Z.C., Ma, H.Q. and Shao, L. (2012) Factors Affecting Global Value Chains Upgrading of China's High-Tech Industry. Journal of Shanghai University of Finance and Economics, 14, 56-64.

[10] Yang, L. and Luo, Y. (2017) China's Outward Foreign Direct Investment and Global Value Chains Upgrading. The Journal of Quantitative \& Technical Economics, 34, 54-70.

[11] Lemoine, F. and Unal, D. (2017) China's Foreign Trade: A "New Normal”. China \& World Economy, 25, 1-21. https://doi.org/10.1111/cwe.12191

[12] Lin, S. (2015) Empirical Study on the Impact of Technological Innovation on the Export Sophistication of China's High-Tech Products Research. Journal of Nanjing University of Finance and Economics, 29, 14-19.

[13] Luo, L.-Y. and Qi, Y. (2016) Technological Innovation Efficiency on the Quality of Export Products of China's Manufacturing Industry Research on the Impact of Upgrading. International Economics and Trade Research, 32, 37-50.

[14] Wang, Z.-X. and Zheng, H.T. (2017) The Non-Complexity of High-Tech Industry Export with Innovation Efficiency Linear Impact. Journal of International Trade, 42, 61-70.

[15] Wang, C.-H. (2011) Clarifying the Effects of R\&D on Performance: Evidence from the High Technology Industries. Asia Pacific Management Review, 16, 51-64.

[16] Wei, L. and Wang, L. (2017) Analysis on the Transformation and Upgrading of China's Manufacturing Industry under Global Value Chains System. The Journal of Quantitative \& Technical Economics, 34, 71-86. 